\title{
Pengembangan Pemindai Dokumen Menjadi Pemindai Telapak Kaki Untuk Identifikasi Flat Foot
}

\author{
Dwi Basuki Wibowo*1, Gunawan Dwi Haryadi ${ }^{1}$, Ariawan Wahyu Pratomo ${ }^{2}$ \\ ${ }^{1}$ Departemen Teknik Mesin, Fakultas Teknik, Universitas Diponegoro \\ Jl. Prof. Sudharto, S.H., Tembalang, Semarang \\ ${ }^{2}$ Jurusan Teknik Mesin, Politeknik Negeri Semarang \\ Jl. Prof. Sudharto, S.H., Tembalang, Semarang \\ *E-mail: rmt.bowo@gmail.com
}

Diterima: 04-12-2019; Direvisi: 20-12-2019; Dipublikasi: 31-12-2019

\begin{abstract}
Abstrak
Di banyak rumah sakit di dunia dalam mengidentifikasi telapak kaki rata (flat foot) masih menggunakan wet foot test. Metode ini tidak akurat karena disamping sulitnya mengetahui penderita benar-benar berdiri tegak saat mencetak telapak kakinya di kertas grafik serta kemungkinan tidak tercetaknya beberapa bagian telapak kaki karena pengecatan awal yang tidak merata. Hasil yang diharapkan diperoleh dari penelitian ini adalah rancang bangun alat pemindai telapak kaki (foot scanner) berbiaya murah menggunakan pemindai dokumen (document scanner) dan perangkat lunak untuk mendefinisikan dan mengkategorikan kaki rata (flat foot) menggunakan metode Cavanagh's arch index (AI). Jejak telapak kaki (footprint) yang dihasilkan alat ini, yang berformat digital, memudahkan dalam mengolah gambar dan menghitung nilai AI-nya dengan perangkat lunak MATLAB.
\end{abstract}

Kata kunci: arch Index; foot scanner; flat foot; MATLAB; wet foot test

\begin{abstract}
The wet foot test is still the most popular method to identify flat feet. This method is inaccurate because it is difficult to know the patient really stands upright when printing the soles of his feet on graph paper and the possibility of not printing some parts of the soles of the feet due to uneven initial painting. The expected results obtained from this study are the design of low-cost foot scanner using a document scanner and software to define and categorize flat feet using the Cavanagh's arch index (AI) method. The footprints produced by this tool, which are in digital format, make it easy to process images and calculate their AI values with MATLAB software.
\end{abstract}

Keywords: arch Index; foot scanner; flat foot; MATLAB; wet foot test

\section{Pendahuluan}

Telapak kaki adalah bagian tubuh yang berfungsi menumpu beban saat berdiri maupun berjalan. Telapak kaki memiliki 3 area lengkungan (arches) yaitu bagian medial, lateral, dan transversal [1]. Area medial memiliki fungsi paling penting untuk mentransfer energi dan menyerap beban kejut saat berjalan/berlari. Berkurangnya area medial arch bisa menyebabkan kehilangan stabilitas serta kemiringan paha bagian bawah (lower limb) yang disebut kaki rata (flat foot) [2].

Tidak seperti penderita adanya jalu di tulang tumit (inferior calcanea spur) yang merasakan nyeri di telapak kaki saat berjalan/berlari [3], penderita flat foot umumnya hanya mengeluh mudah capek. Meskipun pada beberapa kasus ditemukan pasien yang merasakan nyeri di ankle dan knee karena kaki yang tidak lurus [4]. Resiko terjadinya nyeri di knee atau telapak kaki, persoalan pada ankle (ankle weakness), atau kerusakan tulang rawan akibat flat foot ini akan semakin besar bila ditunjang oleh kegemukan, cedera telapak kaki atau ankle, radang sendi, ketuaan, dan penyakit gula [5].

Untuk mengidentifikasi flat foot beberapa rumah sakit di dunia masih menggunakan wet foot test yaitu mencetakkan telapak kaki yang sudah diberi cat ke sebuah kertas berskala (kertas grafik) [6]. Penentuan flat foot atau lengkungan telapak kaki terlalu besar (high arch) dilakukan secara visual dari hasil telapak kaki tercetak (footprint) [7]. Footprint dengan wet foot test ini tidak akurat karena disamping sulitnya mengetahui penderita benar-benar berdiri tegak saat mencetak telapak kakinya serta kemungkinan tidak tercetaknya beberapa bagian telapak kaki karena pengecatan awal telapak kaki yang tidak merata [8]. 
Alat pemindai telapak kaki (foot scanner) dibuat untuk memperbaiki kelemahan metode wet foot test tersebut. Footprint yang dihasilkan yang berformat digital memudahkan dalam pengolahan gambar untuk mendefinisikan dan mengkategorikan flat foot. Rao \& Joseph menggunakan metode penilaian footprint seperti diperlihatkan pada Gambar 1 . Apabila panjang BC kurang dari $1 \mathrm{~cm}$ dikategorikan sebagai high arch (Gambar 1b). Sebaliknya bila panjang AB kurang dari $1 \mathrm{~cm}$ dikategorikan sebagai flat foot (Gambar 1c). Sedangkan semua footprint lainnya dianggap normal (Gambar 1a) [9].

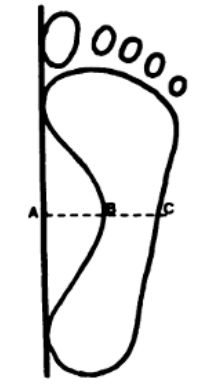

(a) normal

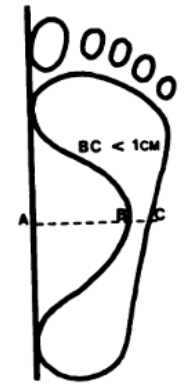

(b) high arch

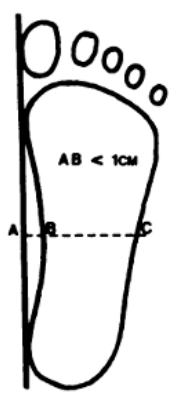

(c) flat foot

Gambar 1. Tipe-tipe telapak kaki

Mirip dengan metode Rao \& Joseph, Kulkarni dkk. mendefinisikan flat foot menggunakan footprint index (FPI) yaitu rasio antara panjang garis bc dan ab, seperti diperlihatkan pada Gambar 2. Apabila nilai FPI $\leq 0.63$, diklasifikasikan flat foot [10]. Metode lain yang hingga sekarang masih digunakan secara luas di dunia adalah Cavanagh's Arch Index (AI) yaitu dari pembagian antara luas telapak kaki tengah dengan keseluruhan luas telapak kaki tanpa jari-jari atau $A I=B /(A+B+C)$, seperti diperlihatkan pada Gambar 3. Apabila $\mathrm{AI} \leq 0.21$, diklasifikasikan high arch, 0.26>AI>0.21 masuk klasifikasi normal dan apabila $\mathrm{AI} \geq 0.26$ diklasifikasikan sebagai flat foot [11].

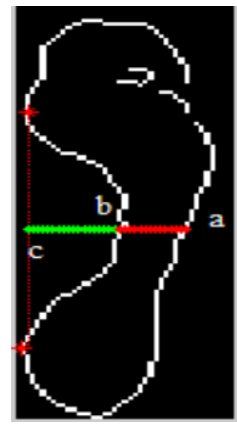

Gambar 2. Metode FPI

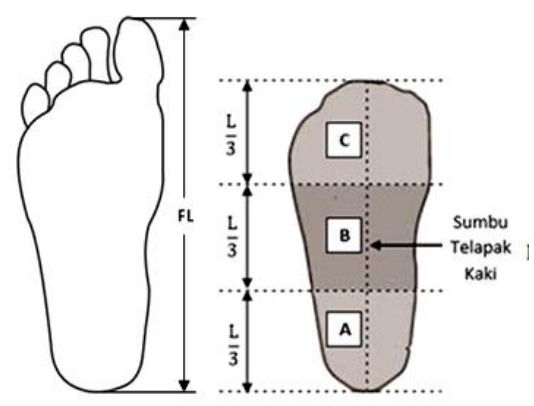

Gambar 3. Metode AI 
Paper ini mengkaji sistem pengukuran bentuk footprint manusia saat berdiri menggunakan scanner dokumen type flatbed yang berharga murah. Scanner flatbed ini juga digunakan oleh Sandy dkk. [12] tetapi untuk menghasilkan bentuk 3D telapak kaki sebagai acuan mendesain sepatu dan Takahashi dkk. untuk pengukuran bentuk 2D telapak tangan untuk berbagai keperluan [13].

\section{Metode Penelitian}

\subsection{Subyek Penelitian}

Seratus dua mahasiswa Departemen Teknik Mesin Universitas Diponegoro diminta melakukan scanning, yang datadatanya ditampilkan seperti pada Tabel 1.

Tabel 1. Data karakteristik subyek penelitian

\begin{tabular}{lcc}
\hline & Rentang nilai & Rata-rata dan SD \\
\hline Umur (tahun) & $17-26$ & $20.0 \pm 1.9$ \\
Jenis kelamin & & $87: 15$ \\
(laki-laki:perempuan) & & $63.3 \pm 13.8$ \\
Berat badan (kg) & $39-129$ & $167.3 \pm 6.8$ \\
Tinggi badan $(\mathrm{cm})$ & $147-185$ & $22.51 \pm 4.16$ \\
BMI $\left(\mathrm{kg} / \mathrm{m}^{2}\right)$ & $15.21-41.60$ & \\
\hline
\end{tabular}

\subsection{Konstruksi Alat Foot Scanner}

Pada penelitian ini digunakan HP Scanjet 200 flatbed scanner ukuran A4. Struktur asli scanner tidak diubah, termasuk jendela kacanya, hanya kerei penutupnya (tray) dilepas. Scanner diletakkan tepat di bawah kaca bening tebal 10 mm (sebagai landasan untuk memindai telapak kaki) yang ditumpu oleh rangka baja agar dapat menahan beban hingga $100 \mathrm{~kg}$. Foot scanner dirancang bisa melakukan scanning 1 telapak kaki secara bergantian, seperti terlihat pada Gambar 4a.

Untuk menghasilkan citra (image) yang jelas, pengaruh cahaya lingkungan harus seminimum mungkin. Proses scanning dilakukan setelah subyek benar-benar berdiri tegak di atas landasan kaca dan telapak kakinya harus bersih [14]. Gambar 4b memperlihatkan hasil scanning telapak kaki kiri salah satu subyek penelitian.

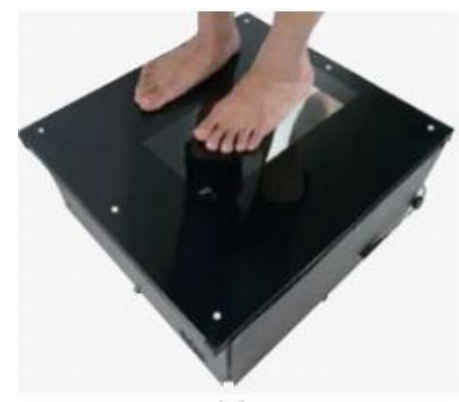

(a)

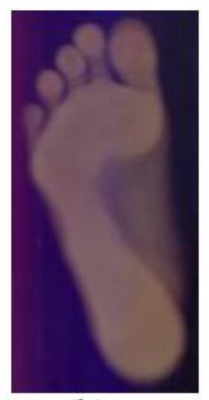

(b)

Gambar 4. Foot scanner

\subsubsection{Menghilangkan Bagian Telapak Kai yang Tidak Berkontak}

Sebelum dilakukan evaluasi bagian telapak kaki yang tidak berkontak dengan landasan harus dihilangkan menggunakan perangkat lunak MATLAB [15]. Prosedurnya adalah sebagai berikut: (1) ubah citra RGB menjadi citra abu- 
abu (Gambar 5a), (2) inputkan nilai index level untuk filter yang terbaik, dan terakhir (3) ubah citra abu-abu menjadi citra hitam-putih. Gambar 5b memperlihatkan hanya telapak kaki yang berkontak saja dengan landasan.

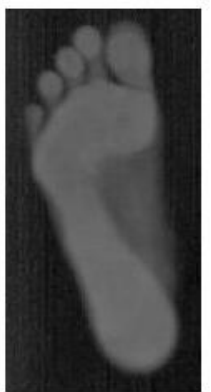

(a)

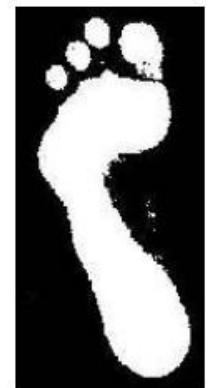

(b)

Gambar 5. Citra telapak kaki salah satu subyek penelitian (resolusi scanner 200 ppi dan index level 110)

\subsubsection{Menghitung Luas dan Dimensi Telapak Kaki}

Luas telapak kaki diperlukan untuk validasi dengan hasil wet foot test 10 subyek yang terbaik dan evaluasi flat foot, Perhitungannya dilakukan menggunakan perangkat lunak MATLAB, tetapi masih dalam bentuk piksel. Untuk mengubahnya menjadi $\mathrm{mm}^{2}$ pada resolusi scanner 200 ppi dapat menggunakan persamaan (1) [16].

$\left(\frac{\text { area in pixels }}{\text { scanner resolution }}\right) \times 645.16 \mathrm{~mm}^{2}$

Perhitungan dimensi telapak kaki seperti panjang telapak kaki (foot length. FL) dan lebar telapak kaki (foot width, FW), seperti nampak pada Gambar 6 [6], diperlukan untuk validasi terhadap hasil wet foot test terbaik. Prosedur perhitungannya menggunakan perangkat lunak MATLAB juga hanya tidak diuraikan di sini karena agak panjang dan rumit.

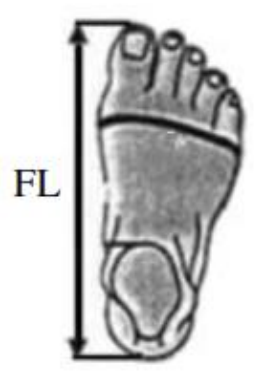

(a)

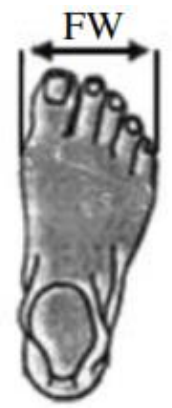

(b)

Gambar 6. Dimensi telapak kaki

\subsubsection{Menghitung Cavanagh's AI}

Pada studi ini identifikasi tipe telapak kaki (flatfoot/high arch) menggunakan metode Cavanagh's AI dengan prosedur sebagai berikut. Gambar garis dari pusat tumit (center of the heel) ke puncak jari telapak kaki ke 2 [14] dan perpanjang garis tersebut hingga ke ujung tumit. Garis ini disebut heel center line (Gambar 7a). Selanjutnya buatlah garis tegak lurus dengan 
heel center line melalui pangkal jari telapak kaki ke 2 untuk menghilangkan jari-jari telapak kaki dan membagi area telapak kaki tanpa jari-jari ke dalam 3 bagian yang sama panjang, seperti nampak pada Gambar $7 b$.

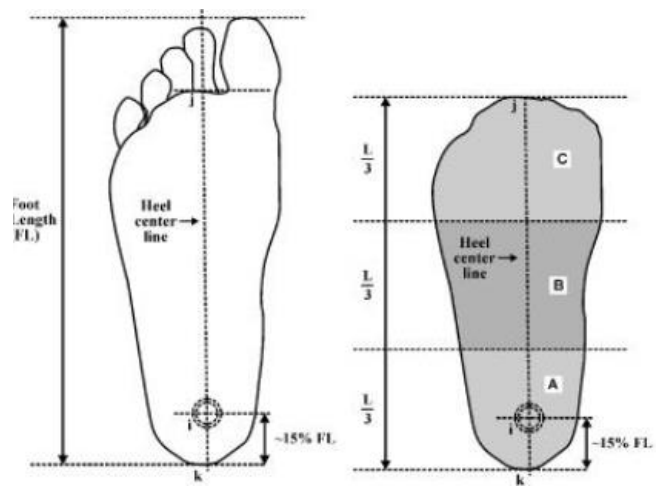

Gambar 7. Identifikasi telapak kaki degan metode Cavanagh's AI

Seluruh prosedur di atas dilakukan menggunakan perangkat lunak MATLAB. AI dihitung dengan membagi luas bagian B dengan seluruh luas telapak kaki tanpa jari-jari kaki, seperti diperlihatkan pada persamaan (2).

$$
\mathrm{AI}=\frac{\mathrm{B}}{(\mathrm{A}+\mathrm{B}+\mathrm{C})}
$$

\section{Hasil dan Pembahasan}

Hasil wet foot test terbaik diperlihatkan pada Gambar 8. Luas telapak kaki dan FL dan FW dihitung berdasarkan jumlah kotak dan dimensi panjang dan lebar kotak pada kertas grafik (dimensi setiap kotak $1 \mathrm{x} 1 \mathrm{~cm}$ ). Perhitungan luas dan dimensi FL dan FW menggunakan foot scanner dilakukan setelah menginputkan nilai index level terbaik (nilainya berbeda pada setiap subyek) untuk menghilangkan bagian telapak kaki yang tidak berkontak, seperti diperlihatkan pada Gambar 9 (resolusi scanner 200 ppi).

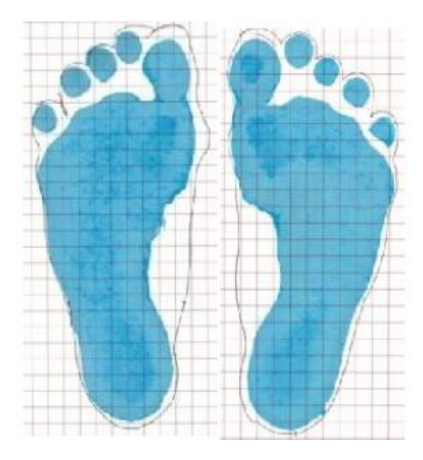

Gambar 8. Hasil wet foot test

Hasil-hasil validasi luas telapak kaki, FL, dan FW antara wet foot test dan foot scanner diperlihatkan pada Tabel 2 dan Tabel 3. Untuk keperluan tersebut 10 mahasiswa diminta melakukan footprint dengan wet foot test dan foot scanner. Dari Tabel 2 terlihat bahwa luas telapak kaki laki-laki lebih besar dari pada perempuan [6, 17]. Perbedaannya berkisar $1662.48 \mathrm{~mm}^{2}$ (dengan rentang 7911-13185 mm²). Nilai rata-rata luas telapak kaki pada resolusi 200 ppi lebih besar dibanding hasil wet foot test dengan error rata-rata $1.22 \%$, sedangkan pada resolusi 300 ppi lebih kecil dibanding hasil wet foot test 
dengan error rata-rata 4.36\%. Pada resolusi 400 ppi terlihat lebih kecil dibanding hasil wet foot test dengan error rata-rata $3.46 \%$, dan terakhir untuk resolusi 600 ppi juga lebih kecil dibanding hasil wet foot test dengan error rata-rata $7.61 \%$.

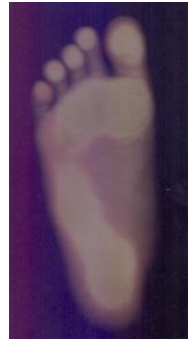

(a)

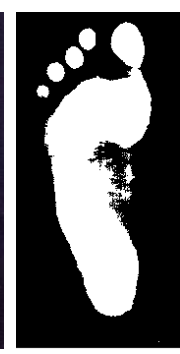

(b)

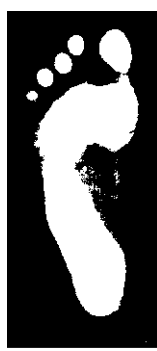

(c)

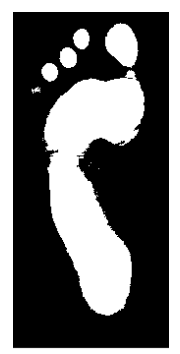

(d)

Gambar 9. Sampwl hasil citra penghilangan telapak kaki yang tidak berkontak: (a) citra hasil scan, (b), (c), (d) setelah difilter dengan index level 105, 107, 110

Perhitungan luas telapak kaki pada wet foot test berdasar jumlah kotak 1 x $1 \mathrm{~cm}$ (Gambar 8) tidak presisi terutama pada bagian tepi telapak kaki dan jari-jari telapak kaki yang memotong sebagian kotak, sehingga area kotak terpotong tersebut harus diperkirakan. Dengan demikian secara natural luas telapak kaki hasil perhitungan wet foot test lebih besar dibanding foot scanner. Hasil penelitian ini juga menunjukkan pengukuran luas telapak kaki dengan resolusi 200 ppi dapat diterima karena nilai mean absolute difference (MAD) antara wet foot test dan foot scanner hanya $1.22 \%$ yang sangat kecil [18].

Besarnya error pada resolusi foot scanner di atas 200 ppi disebabkan oleh semakin besar resolusi bercak-bercak permanen pada kulit telapak kaki yang berkontak semakin jelas terlihat yang mempengaruhi perhitungan luas telapak kaki. Kebenaran argumentasi ini jelas terlihat pada resolusi 600 ppi dengan error $7.61 \%$ dan ilustrasi citranya pada Gambar 10 .
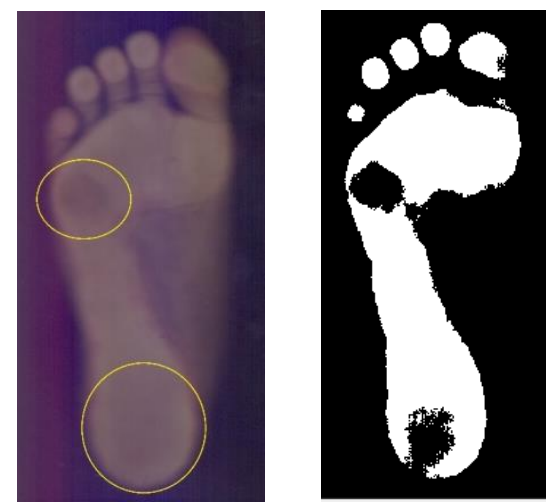

Gambar 10. Ilustrasi citra foot scanner

Dari Tabel 3 terlihat juga bahwa laki-laki memiliki FL dan FW yang lebih panjang dibanding wanita [6]. Perbedaannya berkisar $15.4 \mathrm{~mm}$ (dengan rentang 228.3- $264.8 \mathrm{~mm}$ ) untuk FL dan 3.49 mm (dengan rentang 94.0-107.0 mm) untuk FW. Dari 102 subyek terdapat 31 subyek (30\%) memiliki type telapak kaki normal dengan nilai rata-rata AI=0.240, sementara 63 subyek (62\%) memiliki type telapak kaki flat foot dengan nilai rata-rata $\mathrm{AI}=0.320$, sedangkan sisanya 8 subyek $(8 \%)$ termasuk dalam klasifikasi high arch dengan nilai rata-rata $\mathrm{AI}=0.180$ seperti diperlihatkan pada Tabel 4. Seluruh proses scanning dan pengukuran dilakukan pada resolusi foot scanner 200 ppi dan index level rata-rata 105. 
Tabel 2. Validasi hasil pengukuran luas telapak kaki

\begin{tabular}{lccccc}
\hline \multirow{2}{*}{$\begin{array}{c}\text { Luas Telapak } \\
\text { Kaki }\end{array}$} & Wet Foot & \multicolumn{4}{c}{ Foot Scanner, resolusi rata-rata dan (index level) } \\
\cline { 3 - 6 } & Test & $200 \mathrm{ppi}$ & $300 \mathrm{ppi}$ & $400 \mathrm{ppi}$ & $600 \mathrm{ppi}$ \\
\hline Rata-rata (mm2) & 10165.4 & $10289.00(103)$ & $9722.40(106)$ & $9813.93(106)$ & $9391.93(107)$ \\
SD (mm2) & 1526.95 & $1135.77(4)$ & $919.82(4)$ & $1024.01(4)$ & $1320.71(5)$ \\
$\%$ Error & & -1.22 & 4.36 & 3.46 & 7.61 \\
\hline
\end{tabular}

Table 3. Validasi hasil pengukuran FL dan FW

\begin{tabular}{lccccc}
\hline \multirow{2}{*}{ Dimensi } & Wet Foot Test & \multicolumn{4}{c}{ Foot Scanner, rata-rata dan (SD) } \\
\cline { 3 - 6 } & Rata-rata (SD) & $200 \mathrm{ppi}$ & $300 \mathrm{ppi}$ & $400 \mathrm{ppi}$ & $600 \mathrm{ppi}$ \\
\hline FL (mm) & $253.0(11.30)$ & $231.12(9.27)$ & $231.06(7.83)$ & $237.24(10.62)$ & $236.48(11.04)$ \\
FW (mm) & $100.0(4.60)$ & $94.24(3.80)$ & $93.22(3.94)$ & $95.32(2.34)$ & $96.02(5.10)$ \\
\hline
\end{tabular}

Table 4. Hasil evaluasi type telapak kaki 102 subyek penelitian

\begin{tabular}{|c|c|c|c|c|c|c|c|c|}
\hline \multirow[b]{2}{*}{$\begin{array}{c}\text { Type } \\
\text { Telapak } \\
\text { Kaki }\end{array}$} & \multirow[b]{2}{*}{$\begin{array}{l}\text { Jumlah } \\
\text { Subyek }\end{array}$} & \multirow{2}{*}{$\begin{array}{c}\text { Jenis } \\
\text { Kelamin } \\
\text { (Laki-laki/ } \\
\text { Perempuan) }\end{array}$} & \multicolumn{3}{|c|}{ Rata-rata (Rentang) } & \multicolumn{3}{|c|}{$\mathrm{AI}$} \\
\hline & & & $\begin{array}{c}\text { Berat } \\
\text { Badan } \\
(\mathrm{kg})\end{array}$ & $\begin{array}{l}\text { Tinggi } \\
\text { Badan } \\
(\mathrm{cm})\end{array}$ & $\begin{array}{c}\text { Luas Telapak } \\
\text { Kaki } \\
\left(\mathrm{mm}^{2}\right)\end{array}$ & \multicolumn{2}{|l|}{ Rentang } & $\begin{array}{c}\text { Rata-rata } \\
\text { (SD) }\end{array}$ \\
\hline \multirow{2}{*}{ Normal } & 31 & \multirow{2}{*}{$28 / 3$} & 61.62 & 167.83 & 10602 & 0.210 & - & 0.240 \\
\hline & $(30 \%)$ & & $(39-85)$ & $(147-180)$ & $(7130-13525)$ & 0.260 & & $(0.02)$ \\
\hline Flat & 63 & \multirow{2}{*}{$52 / 11$} & 64.55 & 166.68 & 12687 & 0.261 & - & 0.320 \\
\hline foot & $(62 \%)$ & & $(45-129)$ & $(148-185)$ & $(7044-17071)$ & 0.385 & & $(0.04)$ \\
\hline \multirow{2}{*}{$\begin{array}{l}\text { High } \\
\text { arch }\end{array}$} & \multirow{2}{*}{$8(8 \%)$} & \multirow{2}{*}{$7 / 1$} & 59.38 & 170.38 & 9151 & 0.125 & - & 0.180 \\
\hline & & & $(51-88)$ & $(164-174)$ & $(7455-11489)$ & 0.204 & & $(0.03)$ \\
\hline
\end{tabular}

Terdapat korelasi yang signifikan antara luas telapak kaki (termasuk jari-jari) dengan AI yang dinyatakan oleh persamaan regresi linier $\mathrm{y}=2 \mathrm{E}-05 \mathrm{x}+0.074$ dengan koefisien korelasi $\mathrm{r}=0.72$ untuk keseluruhan 102 subyek, seperti diperlihatkan pada Gambar 11. Pada 63 subyek yang terindikasi flat foot juga terdapat korelasi antara luas telapak kaki dengan AI yang dinyatakan oleh persamaan regresi linier $\mathrm{y}=1 \mathrm{E}-05 \mathrm{x}+0.180$ dengan koefisien korelasi r=0.64, seperti terlihat pada Gambar 12.

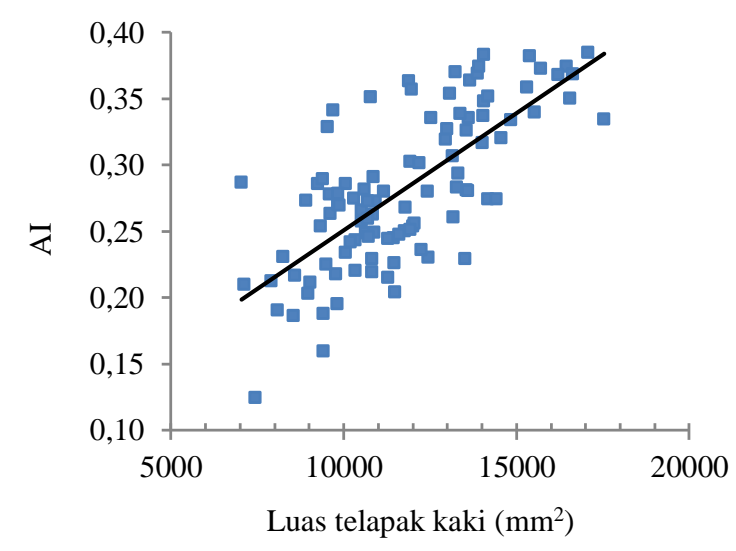

Gambar 11. Grafik Korelasi luas telapak kaki terhadap AI 
Seperti hasil penelitian Chuckpaiwong dkk. [19], pada penelitian ini juga tidak terdapat hubungan antara berat dan tinggi badan dengan AI karena koefisien korelasinya lebih kecil dari 0.40 .

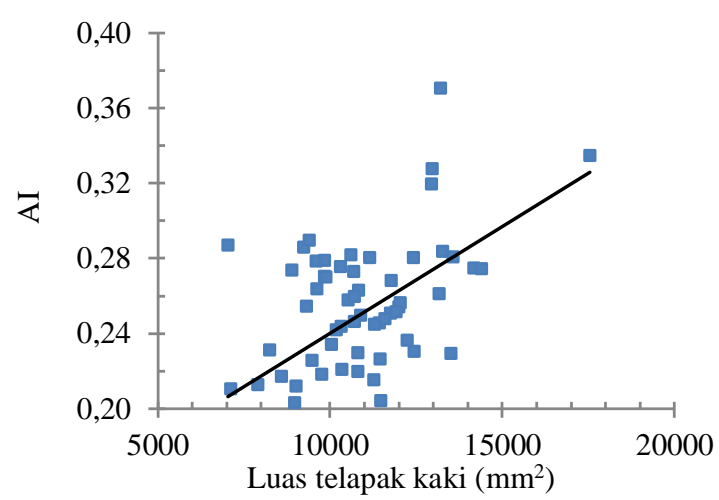

Gambar 12. Grafik Korelasi luas telapak kaki terhadap AI hasil penelitian (19)

\section{Kesimpulan}

Berdasarkan hasil pembahasan penelitian ini maka dapat diambil kesimpulkan sebagai berikut: (1) Flatbed document scanner dengan resolusi 200 ppi dapat digunakan sebagai foot scanner karena MAD-nya sangat kecil (di bawah 2\%), (2) Penetapan resolusi 200 ppi bisa menghemat waktu proses scanning yaitu hanya 15 detik, sedangkan pada resolusi 400 ppi membutuhkan waktu rata-rata 150 detik.

\section{Daftar Pustaka}

[1] Snell R.S., 2004, Clinical Anatomy, (7 ${ }^{\text {th }}$ ed.), Philadelphia: Lippincott Williams \& Wilkins.

[2] Cubucku, S., Alimoglu, M.K., Balci, N., Beyazova, M., 2005, Plantar arch type and strength profile of the majory ankle muscle groups: a morphometric-isokinetic study. Isokinetics and Exercise Science, 13, 217222.

[3] Barrett, S.J., O’Malley, R., 1999, Plantar Faciitis and Other Causes of Heel Pain, Am Fam Physician, 59, $2200-2206$

[4] Gross, K. Douglas, et al., 2011, Flat feet are associated with knee pain and cartilage damage in older adults. NIH Public Access. Arthritis Care Res (Hoboken), 63(7).

[5] Mayo Clinic, Feb 2016, Diseases and conditions flat feet. http://www.mayoclinic.org/diseasesconditions/flatfeet/basics/definition/con-20023429.

[6] Lee, Yu-Chi, Lin, Gloria, Wang J, Mao-Jiun, 2014, Comparing 3D foot scanning with conventional measurement method. Journal of Foot and Ankle Research, 7:44.

[7] Domjanic, Jacqueline, Fieder, Martin, Seider, Horst, and Mitteroecker, Phillipp. 2013, Geometric morphometric footprint analysis of young women. Journal of Foot and Ankle Research, 6:27.

[8] Urry, S.R., Wearing, S.C., 2005, Arch indexes from ink footprints and pressure platforms are different, The Foot 15, 68-73.

[9] Rao, B.U., Joseph, B.J., 1992, The Influence of footwear on the prevalence of flat foot, Journal Bone Joint Surgery [Br]; 74-B: 525-7. 
[10] Kulkarni, P.S., Vinayak, B., 2014, Human footprint properties based on pedobarographic image analysis, International Journal of Advanced Research in Electronics and Communication Engineering (IJARECE). Volume 3, Issue 11.

[11] Cavanagh, P.R., Rodgers, M.M., 1987, The Arch index: a useful measure from footprints, J. Biomechanics Vol. 20, No. 5, pp. 547-551.

[12] Martedi, S., Saito, H., Myriam, S., 2009, Shape measurement system of foot sole surface from flatbed scanner image. MVA2009 IAPR Conference on Machine Vission Application.

[13] Takahashi, T., Aoki, Y., Mochimaru, M., Makiko, K., 2008, Image measurement of hand dimensions based on anatomical structure and creases. In IWAIT 2008.

[14] Rodrigo, A.S., Goonetilleke, R.S., Shuping, X., 2014, Load distribution to minimise pressure-related pain on foot: a model. Ergonomics, Vol. 56, No. 7, 1180-1193.

[15] Gonzalez, R,C., Woods, R.E., Eddins, S.L., 2009, Digital Image Procesing Using MATLAB, Second Edition. Gatesmark Publishing. A Division of Gatesmark, LLC.

[16] Wibowo, D.B., Gunawan, D.H., Widodo, A., Puji, R.S., 2016, Correlation of loaded and unloaded foot area with arch index in younger flatfoot. ICME2016 International Conference on Mechanical and Manufacturing Engineering, August 1-3, 2016.

[17] Periyasamy, R., et al., 2011, "Preliminary investigation of foot pressure distribution variation in men and women adults while standing”, The Foot 21 (2011) $142-148$.

[18] Robinette, K.M., Daanen, H.A.M., 2006, Precision of the CAESAR scan-extracted measurements. Appl Ergon 37(3):259-265.

[19] Chuckpaiwong, B., Nunley, J.A., Mall, N.A., Queen, R.M., 2008, The effect of foot type on in-shoe plantar pressure during walking and running. Gait \& Posture 28 (2008) $405-411$. 